\title{
Facebook Addiction Partially Mediated the Association Between Stress Symptoms and Sleep Disturbance Among Facebook Users
}

\author{
Thi Truc Quynh Ho ${ }^{1}$
}

Accepted: 11 August 2021 / Published online: 18 August 2021

(c) The Author(s), under exclusive licence to Springer Science+Business Media, LLC, part of Springer Nature 2021

\begin{abstract}
Stress symptoms, Facebook addiction, and sleep disturbances have important effects on the health of every individual. However, very few studies have examined the association between stress symptoms, Facebook addiction, and sleep disturbances. This study investigated the mediating effect of Facebook addiction on the association between stress symptoms and sleep disturbances among Facebook users in Vietnam. Three hundred fifty-four Facebook users in Vietnam have completed measures to assess symptoms of stress, levels of Facebook addiction, and sleep disturbances. In the sample, stress was positively associated with sleep disturbances and Facebook addiction partially mediated the association between stress and sleep disturbance (stress was positively associated with Facebook addiction and Facebook addiction was positively associated with sleep disturbances). Thus, our findings demonstrate that stressful individuals tend to be addicted to Facebook, which increase the risk of sleep disturbances. Therefore, interventions aimed at improving sleep quality for Facebook users should focus on reducing stress and reducing dependence on Facebook.
\end{abstract}

Keywords Vietnam · Stress symptoms · Facebook addiction · Sleep disturbances · Mediation

Facebook is the most commonly used social networking site for people to communicate and interact with friends every day (Nida Tabassum Khan \& Sohail Ahmed, 2018). According to statistics, Facebook has more than 2.4 billion members and more than 1.59 billion daily users (Brailovskaia et al., 2020a). Facebook has the ability to give users a sense of connection, belonging, and social support (Brailovskaia \& Margraf, 2018; Brailovskaia et al., 2020a) and increases feelings of own popularity (Nadkarni \& Hofmann, 2012). Hence, individuals are more likely to use Facebook intensively. Individuals who use Facebook excessively tend to be addicted to Facebook (Brailovskaia et al., 2018). According to Elphinston and Noller (2011), Facebook addiction is defined as excessive participation

Thi Truc Quynh Ho

httquynh@hueuni.edu.vn

1 Department of Psychology_Education, University of Education, Hue University, 34 Le Loi, Hue City, Vietnam 
in Facebook activities and is a common cause of problems with daily social functions. Users may be addicted to social aspects of Facebook such as posting, sharing content, or commenting on others' posts, or they may be addicted to other activities such as gaming (Griffiths et al., 2014). Facebook addiction was found to be linked to poor sleep quality (Wolniczak et al., 2013) and psychological problems such as stress (Brailovskaia, et al., 2019a, 2019b; Ryan et al., 2014), anxiety (Zaffar et al., 2015), and depression (Mamun, \& Griffiths, 2019; Foroughi et al., 2019). Excessive using of social media or Facebook can lead to three problems in relationships (jealousy, loneliness, and lack of care) (Nongpong \& Charoensukmongkol, 2016), envy, and social comparison (Charoensukmongkol, 2018), which in turn leads to psychological problems (Appel et al., 2016; Moeller \& Seehuus, 2019).

Stress refers to the complex interaction between an individual and their environment that may affect one's well-being (Lazarus \& Folkman, 1984). According to Lee et al. (2013), stress has been identified as harmful to sleep habits and health conditions. Increased stress levels are related to individuals' poor sleep quality (Almojali et al., 2017; Lund et al., 2010). Many people have reported that when the quantity and quality of their sleep decreased, the stress level increased. On the contrary, several other studies have reported that stressful individuals increase the likelihood of experiencing poor quality sleep (Almojali et al., 2017; Drake et al., 2014). Physiologically, the relationship between stress and sleep quality can be explained as follows: stress is accompanied by a reduction in slow wave and rapid eye movement, and lack of sleep as a source of stress has a significant impact on circadian rhythm and sleep architecture (Van Reeth et al., 2000).

Regarding the association between stress and sleep disturbance, Lee et al. (2013) reported that individuals with high stress levels are more likely to experience sleep disturbances. According to Pillai et al. (2014), exposure to stressful events impaired normal sleep function of individuals. On the other hand, Kalmbach et al. (2018) and Brailovskaia et al., (2019a, 2019b) synthesized and listed factors that could buffer the relationship between stress and sleep disturbance, including greater stressor chronicity, negative event appraisal, greater substance misuse, poor coping, negative cognitive-emotional, and depression symptoms. Accordingly, the factors listed above increase the risk and severity of sleep disturbances after the individual experiences stress (Kalmbach et al., 2018).

\section{Facebook Addiction as a Mediator}

Many previous studies have investigated the association between stress and Facebook addiction as well as the association between Facebook addiction and sleep quality. First of all, previous studies reported that stress was positively correlated to Facebook addiction (Brailovskaia, et al., 2019a, b; Ryan et al., 2014). Ryan et al. (2014) revealed that individuals with high stress levels are more likely to be addicted to Facebook. Individuals tend to use Facebook to escape from daily stress (Brailovskaia \& Bierhoff, 2016), seek relief, and receive social support (Ryan et al., 2014). On Facebook, individuals can play online games, promote him/ herself, and communicate and exchange interesting information (Brailovskaia \& Bierhoff, 2016). Moreover, using Facebook can promote happiness and life satisfaction (Brailovskaia \& Margraf, 2016; Kim \& Lee, 2011). Hence, individuals are more likely to overuse Facebook, which in turn increases the risk of developing Facebook addiction (Brailovskaia \& Margraf, 2017). Then, prior studies have indicated that there is a strong link between social network sites use and/or Facebook use and the quality of sleep (Bowler \& Bourke, 2019; Wolniczak et al., 
2013; Xanidis \& Brignell, 2016). Recently, a longitudinal study demonstrated that Facebook addiction predicted insomnia and depression in a sample of German inpatients (Brailovskaia, et al., 2019a, 2019b). However, little is known about the link between Facebook addiction and sleep disturbances. Sleep disturbances include disturbances in the initiation and maintenance of sleep, excessive somnolence disturbances, disturbances in the sleep-wake schedule, and dysfunction related to sleep, sleep phase, or partial arousals (René E Cormier, 1990). Sleep disturbance has been proven to be linked to poor health outcomes (Levenson et al., 2016). There are many factors that contribute to sleep disturbance in individuals including biological, psychosocial, and environmental factors (Levenson et al., 2016). Facebook addiction is one of the factors that can cause sleep disturbances in individuals. Previous studies have revealed that greater social media or electronic media use was significantly related to sleep disturbance (Lemola et al., 2015; Levenson et al., 2016). Xanidis and Brignell (2016) have indicated that social network sites dependence was associated with decreased sleep quality (sleep disturbance is one of the seven components of sleep quality). This finding is in line with earlier findings that excessive use of social media sites is strongly linked to poor sleep quality (Andreassen et al., 2012; Wolniczak et al., 2013). On the other hand, Wolniczak et al. (2013); Bowler and Bourke (2019); and Atroszko et al. (2018) reported that Facebook using and Facebook addiction are strongly associated with poor sleep quality. International studies from different regions have revealed that using social media can reduce sleep duration and more frequent disturbances (Alonzo et al., 2020). Using social media/electronic media/social network sites/social network sites dependence/Facebook addiction can cause poor sleep quality or sleep disturbances in three ways (Cain \& Gradisar, 2010). Firstly, as the time spent on social media increases, their sleep time may decrease (Wolniczak et al., 2013). Secondly, when using social media, individuals tend to experience cognitive, emotional, and/or physiological arousal (Bruni et al., 2015), thereby causing sleep disturbances. Finally, the bright light from social media devices may delay the circadian rhythm (Chang et al., 2015). The above analysis shows that in the literature, correlations between stress symptoms and Facebook addiction as well as between Facebook addiction and sleep disorders have been confirmed. In Vietnam, an estimated of 3.4 to $18.5 \%$ of the Vietnamese population has symptoms of stress (T. T. T. Tran et al., 2019; H. T. Le et al., 2020). On the other hand, there are nearly 75 million Facebook users (accounting for about 75\% of Vietnam's population). People aged from 25 to 34 were the largest user group (Napoleoncat, 2021). In previous studies, an estimated of 26.6 to $80.9 \%$ of the Vietnamese population self-report poor sleep quality (T. A. Le et al., 2019; Zhang et al., 2017). However, little is known about the relationship between stress symptoms, Facebook addiction, and sleep quality in the Vietnamese sample. In the literature, there are very few studies investigating the mediating effects of Facebook addiction on the association between stress symptoms and sleep disturbances. To fill this gap in the literature and expand on previous studies, this study investigated a simple model in which Facebook addiction mediates the association between stress symptoms and sleep disturbance in a Vietnamese sample.

\section{This Study}

This study aims to examine the following hypotheses:

Hypothesis 1: Stress symptoms would be positively associated with sleep disturbances among Vietnamese Facebook users. 
Hypothesis 2: Stress symptoms would be positively associated with Facebook addiction among Vietnamese Facebook users.

Hypothesis 3: Facebook addiction would be positively associated with sleep disturbances among Vietnamese Facebook users.

Hypothesis 4: Facebook addiction would mediate the association between stress symptoms and sleep disturbances among Vietnamese Facebook users.

\section{Methods}

\section{Sample}

Survey data was collected from October 3 to October 27, 2020 (before COVID-19 outbreak). All participants belong to an administrative body in central Vietnam (population size $=3107$ ). The process of recruiting participants is carried out according to the following steps: (1) request approval from agency leader; (2) schedule a meeting with the participants; (3) inform the purpose of the study and ask for help; (4) sign the consent form to participate in the study; (5) instructions to answer the questionnaire; and (6) make friends via Facebook with the study participants and share the survey link. Participant selection criteria included Facebook users and people who can read and understand Vietnamese. A total of 361 Facebook users agreed to participate in the study and complete the questionnaire. However, only 354 questionnaires were valid (accounting for $98.06 \%$ ). Of the participants, 59.3\% were females. Participants ages ranged from 15 to 49, with the average age is $25.13(\mathrm{SD}=7.23)$. Facebook users completed the measures to assess their stress symptoms, Facebook addiction levels, and sleep disturbances. Participants received $50,000 \mathrm{VND}$ (equivalent to USD 2.17) after completing the questionnaire.

\section{Measures}

In this study, the measuring tools used included depression, anxiety, and stress scale 21; Bergen Facebook addiction scale; and the Pittsburgh sleep quality index. The Vietnamese version of all 3 scales has good internal reliability (T. D. Tran et al., 2013; M. T. H. Le et al., 2017; To \& Nguyen, 2015).

Depression, Anxiety, and Stress Scale 21 (DASS 21) Stress symptoms was measured using the 7-item depression, anxiety, and stress scale 21 (Lovibond \& Lovibond, 1995). A sample item is "I found myself getting agitated." Stress score can be calculated by summing the scores of seven items and then multiplying by 2 . Participants rated each item on a 4-point scale, ranging from 0 (never) to 3 (almost always). Cut-off scores of 0-7 (normal), 8-9 (mild stress), 10-12 (moderate stress), 13-16 (severe stress), and 17-42 (extremely severe stress) are recommended. The alpha coefficient in this study for the stress subscale was 0.86 .

Bergen Facebook Addiction Scale (BFAS) We evaluated users' Facebook addiction levels using 6-item BFAS (Andreassen et al., 2012). An example item is "You use Facebook in order to forget about personal problems." Participants rated on a 5-point scale from 1 (very rarely) to 5 (very often). If the participant points out "often" or "very often" on at least 4 
of the 6 items, this could be an indicator of higher risk of Facebook addiction (Andreassen et al., 2012). In this study, the alpha coefficient for the six items was 0.81 .

The Pittsburgh Sleep Quality Index (PSQI) Sleep disturbance was examined by the sleep disturbance component of PSQI (Buysse et al., 1989). The sleep disturbance component consisted of 9 causes (corresponding to 9 items) of trouble sleeping (e.g., "have to get up to use the bathroom" and "cannot breathe comfortably") in the past month. Participants were asked to rate each item on a 4-point scale, ranging from 0 (not during the past month) to 3 (three or more times a week). Sleep disturbance scores range from 0 to 3 . In this study, the alpha coefficient for the nine items was 0.78 .

\section{Data Analysis}

Statistical analyses were conducted using IBM SPSS Statistics v.20. Firstly, we compute the mean and standard deviations of all the variables studied. Secondly, a correlation matrix of Pearson that included stress, Facebook addiction, and sleep disturbances was developed. Thirdly, we use Amos 20.0 to calculate the mediation model fit indices. Base on the previous studies (Hair et al., 2006; Schumacker \& Lomax, 2004; Hu \& Bentler, 1999; Seyal et al., 2002; Kline, 1998), we have listed the standard fit indices for the mediation model (see Table 2). Finally, to identify the mediating effect of Facebook addiction in the association between stress and sleep disturbances, we used Hayes' SPSS PROCESS macro v3.5 (Model 4) (Hayes, 2012) with gender and age controlled. Mediation analysis results with PROCESS macro will present indirect effect with effect size and confidence intervals (CI). The CI does not contain zero, which indicates that the indirect effect is significant.

\section{Results}

\section{Participant Characteristics}

In this study, we found that $45.2 \%$ of users experienced stress, and $33.6 \%$ of users were at risk of being addicted to Facebook. In terms of sleep disturbance, $68.1 \%$ of Facebook users suffer from sleep disturbance less than once a week; 22.6\% of Facebook users suffer from sleep disturbance once or twice a week; $1.4 \%$ of Facebook users suffer from sleep disturbance three or more times a week; and 7.9\% of Facebook users have not experienced sleep disturbances in the past month.

\section{Preliminary Analysis}

Table 1 presents the mean score, standard deviation, and correlation between symptoms of stress, Facebook addiction, and sleep disturbances (see Table 1). Table 1 revealed that Facebook addiction was significantly positively correlated to sleep disturbances and stress symptoms. Stress symptoms were significantly positively correlated with sleep disturbances. 
Table 1 Pearson correlations, mean, and standard deviations among study variables

\begin{tabular}{llllll}
\hline & Min-Max & Mean & SD & Facebook addiction & Stress \\
\hline Facebook addiction & $6-26$ & 14.42 & 4.577 & - & - \\
Stress & $0-42$ & 14.85 & 9.093 & $0.321^{* *}$ & - \\
Sleep disturbances & $0-3$ & 1.18 & 0.576 & $0.229^{* *}$ & $0.420^{* *}$ \\
\hline
\end{tabular}

Notes: $n$ (sample size $)=354, * *$ correlation is significant at the 0.01 level (two-tailed), SD standard deviation

Table 2 Model fit statistics

\begin{tabular}{lll}
\hline Indices & $\begin{array}{l}\text { Reference standard (Hair et al., 2006; Schumacker \& Lomax, } \\
\text { 2004; Hu \& Bentler, 1999; Seyal et al., 2002; Kline, 1998) }\end{array}$ & Mediation model \\
\hline$\chi^{2} / d f$ & $<5$ & 2.651 \\
$G F I$ & $>0.85$ & 0.876 \\
NFI & $>0.80$ & 0.800 \\
$C F I$ & $>0.80$ & 0.864 \\
AGFI & $>0.80$ & 0.848 \\
RMSEA & $<0.08$ & 0.068
\end{tabular}

Notes: $n$ (sample size) $=354, \chi^{2} / \mathrm{df}=$ Chi-square/df, $C F I$ comparative fix index, $R M S E A$ root mean square errors of approximation, AGFI adjusted goodness of fix, GFI goodness of fix index, NFI normed fit index

Table 3 Bias-corrected bootstrap test on mediating effects

\begin{tabular}{lcccc}
\hline Paths & $\beta$ & $S E$ & \multicolumn{2}{l}{$95 \% C I$} \\
\cline { 4 - 5 } & & & Low & High \\
\hline Stress-sleep disturbances & $0.027^{* * *}$ & 0.003 & 0.020 & 0.033 \\
Stress-Facebook addiction & $0.134^{* * *}$ & 0.026 & 0.083 & 0.186 \\
Facebook addiction-sleep disturbances & $0.017^{* *}$ & 0.065 & 0.004 & 0.030 \\
Indirect effect & $0.002^{* * *}$ & 0.001 & 0.001 & 0.004 \\
Age-Facebook addiction & $-0.122^{* * *}$ & 0.033 & -0.187 & -0.058 \\
Gender-Facebook addiction & 0.093 & 0.460 & -0.811 & 0.997 \\
Age-sleep disturbances & $0.011^{* * *}$ & 0.004 & 0.003 & 0.019 \\
Gender-sleep disturbances & $-0.062^{*}$ & 0.056 & -0.171 & 0.047 \\
\hline
\end{tabular}

Notes: $n$ (sample size $)=354 . B$ standardized (regression) coefficients, $S E$ standard error, $C I$ confidence interval. $* * *$ correlation is significant at the 0.001 level (two-tailed), $* *$ correlation is significant at the 0.01 level (two-tailed)

\section{Mediation Model Analysis}

Table 2 presents the fit indicators of the mediation model. According to Table 2, the mediation model showed acceptable fit statistics (see Table 2).

Table 3 presents direct and indirect effects from stress symptoms to sleep disturbances. According to Table 3 and Fig. 1, the direct effects from stress symptoms to Facebook addiction, from Facebook addiction to sleep disturbances as well as from stress symptoms 


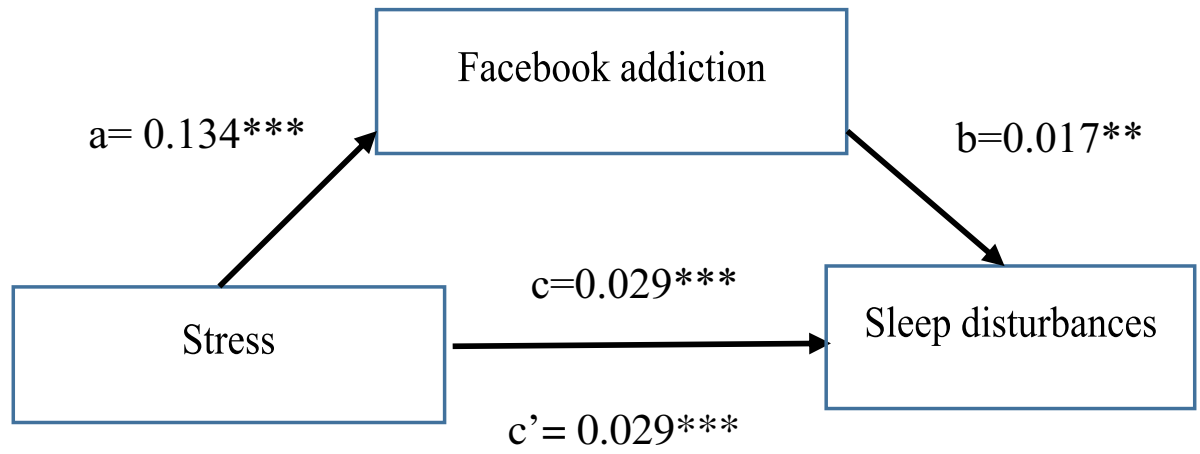

Fig. 1 Mediation model of the indirect effect of stress on sleep disturbances. For the stress-sleep disturbances pathway, the $c$ values represent the total effect and the $c$ ' values represent the direct effect

to sleep disturbances are significant. The indirect effect from stress symptoms to sleep disturbances through Facebook addiction is also significant (see Table 2). These results proved that Facebook addiction partially mediated the relationship between stress symptoms and sleep disturbances (see Fig. 1).

\section{Discussion}

Sleep plays an important role in promoting the good health of each individual (Buysse, 2014). Sleep disturbance is one of the many aspects that can reflect an individual's poor sleep quality. Many previous studies have focused on poor sleep quality and factors that influence poor sleep quality. However, research investigating the factors that influence sleep disturbances is rare, especially in Vietnam. This work is designed to investigate the mediating role of Facebook addiction in the association between stress symptoms and sleep disturbances among Facebook users. This study found significant relationships that contribute to a better understanding of sleep disturbances and potential ways to improve sleep quality.

Previous studies have demonstrated that stress is positively associated with sleep disturbances (Brailovskaia, et al., 2019a, b; Kalmbach et al., 2018; Lee et al., 2013). Consistent with previous findings, we found that Facebook users with high stress levels had a higher risk of sleep disturbances, which supports hypothesis 1 of this study. Presumptive interpretations of the relationship between stress and sleep disturbance could be that stress alters circadian rhythms and sleep structure (Van Reeth et al., 2000). Furthermore, stress can impair a person's normal sleep function (Pillai et al., 2014).

Ryan et al. (2014) and Brailovskaia et al., (2019a, b) indicated that stress was positively correlated to Facebook addiction. In line with previous findings, this study revealed that Facebook users with high stress levels are more likely to be addicted to Facebook, which supports hypothesis 2. Then, we found that Facebook users with higher Facebook addiction scores were at a higher risk of developing sleep disturbances, which supports hypothesis 3. This finding is consistent with previous findings (Andreassen et al., 2012; Bowler \& Bourke, 2019; Wolniczak et al., 2013; Xanidis \& Brignell, 2016). Therefore, Facebook addiction partially mediated the association between stress and sleep disturbance among Facebook users, which supports hypothesis 4. Presumptive interpretations of the association between stress, Facebook addiction, and sleep disturbance might be that Facebook 
users with a high level of stress tend to use Facebook for seeking social support or emotional relief. And users can become addicted to Facebook when they have a lot of positive experiences with it (Ryan et al., 2014). When using Facebook, the bright light from electronic devices can delay the circadian rhythms. The time spent on Facebook has increased, and the sleep time of Facebook users will decrease, especially using Facebook before bedtime. On the other hand, Facebook users may experience cognitive, emotional, and physiological arousal while using Facebook, leading to sleep disturbances (Bruni et al., 2015; Chang et al., 2015; Wolniczak et al., 2013).

Our study consists limitations. Firstly, this study used self-reporting method; thus, the findings of this study depend heavily on the self-reported results of participants. Secondly, all analyses are based on cross-sectional studies, which do not allow to determine cause and effect. Finally, the study was performed on a small sample of healthy participants using Facebook, not a large clinical sample.

In the context of the above limitations, this study has the following implications: our study extended previous studies by investigating the mediating role of Facebook addiction in the association between stress symptoms and sleep disturbance in a sample of Vietnamese Facebook users. The results of this study contribute to the literature on sleep quality by emphasizing that Facebook addiction plays an important role in the association between stress and sleep disturbances among Facebook users. The higher level of stress leads to the risk of Facebook addiction, which in turn leads to sleep disturbances. Furthermore, the findings of this study imply that interventions aimed at reducing sleep disturbances for users with symptoms of stress should focus on reducing dependence on Facebook or reducing time spent on Facebook. Previous empirical studies (Brailovskaia et al., 2020b; Tromholt, 2016) indicated that quitting Facebook or using Facebook less is associated with increased life satisfaction and well-being, increased physical activity, and reduced symptoms of depression and smoking behavior. Therefore, less use of Facebook is necessary for stressed individuals to improve their sleep quality and well-being and promote a healthier lifestyle. Therefore, schools and social institutions should increase awareness of Facebook addiction and dark side of Facebook in general. This can be implemented by launching campaigns and talks to help participants understand the negative effects of Facebook addiction on their health and sleep quality, and understand mechanisms of the path from stress to sleep disturbances.

Acknowledgements The author would like to thank the participants who accepted the questionnaires to complete this study.

\section{Declarations}

Conflict of Interest The author declares no competing interests.

Consent to Participate Informed consent was obtained from all individual participants included in this study.

\section{References}

Almojali, A. I., Almalki, S. A., Alothman, A. S., Masuadi, E. M., \& Alaqeel, M. K. (2017). The prevalence and association of stress with sleep quality among medical students. Journal of Epidemiology and Global Health, 7(3), 169.

Alonzo, R., Hussain, J., Stranges, S., \& Anderson, K. K. (2020). Interplay between social media use, sleep quality, and mental health in youth: A systematic review. Sleep Medicine Reviews, 101414. 
Andreassen, C. S., Torsheim, T., Brunborg, G. S., \& Pallesen, S. (2012). Development of a Facebook addiction scale. Psychological Reports, 110(2), 501-517.

Appel, H., Gerlach, A. L., \& Crusius, J. (2016). The interplay between Facebook use, social comparison, envy, and depression. Current Opinion in Psychology, 9, 44-49.

Atroszko, P. A., Balcerowska, J. M., Bereznowski, P., Biernatowska, A., Pallesen, S., \& Schou Andreassen, C. (2018). Facebook addiction among Polish undergraduate students: Validity of measurement and relationship with personality and well-being. Computers in Human Behavior, 85, 329-338.

Bowler, J., \& Bourke, P. (2019). Facebook use and sleep quality: Light interacts with socially induced alertness. British Journal of Psychology, 110(3), 519-529.

Brailovskaia, J., \& Bierhoff, H.-W. (2016). Cross-cultural narcissism on Facebook: Relationship between self-presentation, social interaction and the open and covert narcissism on a social networking site in Germany and Russia. Computers in Human Behavior, 55, 251-257.

Brailovskaia, J., Schillack, H., \& Margraf, J. (2018). Facebook addiction disorder in Germany. Cyberpsychology, Behavior, and Social Networking, 21(7), 450-456.

Brailovskaia, J., Rohmann, E., Bierhoff, H.-W., Margraf, J., \& Köllner, V. (2019a). Relationships between addictive Facebook use, depressiveness, insomnia, and positive mental health in an inpatient sample: A German longitudinal study. Journal of Behavioral Addictions, 8(4), 703-713. https://doi.org/10.1556/2006.8.2019.63

Brailovskaia, J., Velten, J., \& Margaf, J. (2019b). Relationship between daily stress, depression symptoms, and Facebook addiction disorder in Germany and in the United States. Cyberpsychology, Behavior, and Social Networking, 22(9), 610-614.

Brailovskaia, J., \& Margraf, J. (2016). Comparing Facebook users and Facebook non-users: Relationship between Personality traits and mental health variables - An exploratory study. PLOS ONE, 11(12), e0166999.

Brailovskaia, J., \& Margraf, J. (2017). Facebook addiction disorder (FAD) among German students-A longitudinal approach. PLOS ONE, 12(12), e0189719.

Brailovskaia, J., \& Margraf, J. (2018). What does media use reveal about personality and mental health? An exploratory investigation among German students. PLOS ONE, 13(1), e0191810.

Brailovskaia, J., Bierhoff, H.-W., Rohmann, E., Raeder, F., \& Margraf, J. (2020a). The relationship between narcissism, intensity of Facebook use, Facebook flow and Facebook addiction. Addictive Behaviors Reports, 11, 100265.

Brailovskaia, J., Ströse, F., Schillack, H., \& Margraf, J. (2020b). Less facebook use - More well-being and a healthier lifestyle? An experimental intervention study. Computers in Human Behavior, 108, 106332. https://doi.org/10.1016/j.chb.2020.106332

Bruni, O., Sette, S., Fontanesi, L., Baiocco, R., Laghi, F., \& Baumgartner, E. (2015). Technology use and sleep quality in preadolescence and adolescence. Journal of Clinical Sleep Medicine, 11(12), 1433-1441.

Buysse, D. J. (2014). Sleep health: Can we define it? Does it matter? Sleep, 37(1), 9-17.

Buysse, D. J., Reynolds, C. F., Monk, T. H., Berman, S. R., \& Kupfer, D. J. (1989). The Pittsburgh sleep quality index: A new instrument for psychiatric practice and research. Psychiatry Research, 28(2), 193-213.

Cain, N., \& Gradisar, M. (2010). Electronic media use and sleep in school-aged children and adolescents: A review. Sleep Medicine, 11(8), 735-742.

Chang, A.-M., Aeschbach, D., Duffy, J. F., \& Czeisler, C. A. (2015). Evening use of light-emitting eReaders negatively affects sleep, circadian timing, and next-morning alertness. Proceedings of the National Academy of Sciences, 112(4), 1232-1237.

Charoensukmongkol, P. (2018). The impact of social media on social comparison and envy in teenagers: The moderating role of the parent comparing children and in-group competition among friends. Journal of Child and Family Studies, 27(1), 69-79. https://doi.org/10.1007/s10826-017-0872-8

René E Cormier. (1990). Sleep disturbances. In H. J. In Walker HK, Hall WD (Ed.), Clinical Methods: The History; Physical; and Laboratory Examinations. 3rd edition. Butterworth.

Drake, C. L., Pillai, V., \& Roth, T. (2014). Stress and sleep reactivity: A prospective investigation of the stress-diathesis model of insomnia. Sleep, 37(8), 1295-1304.

Elphinston, R. A., \& Noller, P. (2011). Time to face it! Facebook intrusion and the implications for romantic jealousy and relationship satisfaction. Cyberpsychology, Behavior, and Social Networking, 14(11), 631-635.

Foroughi, B., Iranmanesh, M., Nikbin, D., \& Hyun, S. S. (2019). Are depression and social anxiety the missing link between Facebook addiction and life satisfaction? The interactive effect of needs and self-regulation. Telematics and Informatics, 43, 101247. 
Griffiths, M. D., Kuss, D. J., \& Demetrovics, Z. (2014). Social networking addiction. In Behavioral Addictions (pp. 119-141). Elsevier.

Hair, J. F., Black, W. C., Babin, B.J., Anderson R. E., \& T. R. L. (2006). Multivariate data analysis 6th Edition. Pearson University Press.

Hayes, A. F. (2012). PROCESS: A versatile computational tool for observed variable moderation, mediation, and conditional process modeling. Manuscript Submitted for Publication.

Hu, L., \& Bentler, P. M. (1999). Cutoff criteria for fit indexes in covariance structure analysis: Conventional criteria versus new alternatives. Structural Equation Modeling: A Multidisciplinary Journal, 6(1), 1-55. https://doi.org/10.1080/10705519909540118.

Kalmbach, D. A., Anderson, J. R., \& Drake, C. L. (2018). The impact of stress on sleep: Pathogenic sleep reactivity as a vulnerability to insomnia and circadian disorders. Journal of Sleep Research, 27(6), e12710.

Kim, J., \& Lee, J.-E.R. (2011). The Facebook paths to happiness: Effects of the number of facebook friends and self-presentation on subjective well-being. Cyberpsychology, Behavior, and Social Networking, 14(6), 359-364.

Kline, R. B. (1998). Methodology in the social sciences. Guilford Press.

Lazarus, R. S., \& Folkman, S. (1984). Stress, Appraisal, and Coping. Springer.

Le, M. T. H., Tran, T. D., Holton, S., Nguyen, H. T., Wolfe, R., \& Fisher, J. (2017). Reliability, convergent validity and factor structure of the DASS-21 in a sample of Vietnamese adolescents. PLOS ONE, 12(7), e0180557. https://doi.org/10.1371/journal.pone.0180557.

Le, T. A., Dang, A. D., Tran, A. H. T., Nguyen, L. H., Nguyen, T. H. T., Phan, H. T., Latkin, C. A., Tran, B. X., Ho, C. S. H., \& Ho, R. C. M. (2019). Factors associated with sleep disorders among methadone-maintained drug users in Vietnam. International Journal of Environmental Research and Public Health, 16(22), 4315.

Le, H. T., Lai, A. J. X., Sun, J., Hoang, M. T., Vu, L. G., Pham, H. Q., Nguyen, T. H., Tran, B. X., Latkin, C. A., Le, X. T. T., Nguyen, T. T., Pham, Q. T., Ta, N. T. K., Nguyen, Q. T., Ho, R. C. M., \& Ho, C. S. H. (2020). Anxiety and depression among people under the nationwide partial lockdown in Vietnam. Frontiers in Public Health, 8, 589359.

Lee, S.-Y., Wuertz, C., Rogers, R., \& Chen, Y.-P. (2013). Stress and sleep disturbances in female college students. American Journal of Health Behavior, 37(6), 851-858.

Lemola, S., Perkinson-Gloor, N., Brand, S., Dewald-Kaufmann, J. F., \& Grob, A. (2015). Adolescents' electronic media use at night, sleep disturbance, and depressive symptoms in the Smartphone Age. Journal of Youth and Adolescence, 44(2), 405-418.

Levenson, J. C., Shensa, A., Sidani, J. E., Colditz, J. B., \& Primack, B. A. (2016). The association between social media use and sleep disturbance among young adults. Preventive Medicine, 85, 36-41.

Lovibond, P. F., \& Lovibond, S. H. (1995). The structure of negative emotional states: Comparison of the Depression Anxiety Stress Scales (DASS) with the Beck Depression and Anxiety Inventories. Behaviour Research and Therapy, 33(3), 335-343.

Lund, H. G., Reider, B. D., Whiting, A. B., \& Prichard, J. R. (2010). Sleep patterns and predictors of disturbed sleep in a large population of college students. Journal of Adolescent Health, 46(2), 124-132.

Mamun, M. A. A. I., \& Griffiths, M. D. (2019). The association between Facebook addiction and depression: A pilot survey study among Bangladeshi students. Psychiatry Research, 271, 628-633.

Moeller, R. W., \& Seehuus, M. (2019). Loneliness as a mediator for college students' social skills and experiences of depression and anxiety. Journal of Adolescence, 73, 1-13.

Nadkarni, A., \& Hofmann, S. G. (2012). Why do people use Facebook? Personality and Individual Differences, 52(3), 243-249.

Napoleoncat. (2021). Facebook users in Viet Nam. https://napoleoncat.com/stats/facebook-users-in-viet_ nam/2021/03.

Nida Tabassum Khan \& Sohail Ahmed. (2018). Impact of Facebook addiction on students academic performance. Research in Medical \& Engineering Sciences, 5(2).

Nongpong, S., \& Charoensukmongkol, P. (2016). I don't care much as long as i am also on Facebook. The Family Journal, 24(4), 351-358. https://doi.org/10.1177/1066480716663199.

Pillai, V., Roth, T., Mullins, H. M., \& Drake, C. L. (2014). Moderators and mediators of the relationship between stress and insomnia: Stressor chronicity, cognitive intrusion, and coping. Sleep, 37(7), 1199-1208A.

Ryan, T., Chester, A., Reece, J., \& Xenos, S. (2014). The uses and abuses of Facebook: A review of Facebook addiction. Journal of Behavioral Addictions, 3(3), 133-148.

Schumacker, R. E., \& Lomax, R. G. (2004). A Beginner's guide to structural equation modeling (2nd ed.). Lawrence Erlbaum. Routledge. 
Seyal, A. H., Rahman, M. N. A., \& Rahim, M. M. (2002). Determinants of academic use of the Internet: A structural equation model. Behaviour \& Information Technology, 21(1), 71-86. https://doi.org/10. $1080 / 01449290210123354$.

To, N., \& Nguyen, N. (2015). Validity of the Vietnamese version of the Pittsburgh sleep quality index. Sleep Medicine, 16, S52.

Tran, T. D., Tran, T., \& Fisher, J. (2013). Validation of the depression anxiety stress scales (DASS) 21 as a screening instrument for depression and anxiety in a rural community-based cohort of northern Vietnamese women. BMC Psychiatry, 13(1), 24.

Tran, T. T. T., Nguyen, N. B., Luong, M. A., Bui, T. H. A., Phan, T. D., Tran, V. O., Ngo, T. H., Minas, H., \& Nguyen, T. Q. (2019). Stress, anxiety and depression in clinical nurses in Vietnam: A crosssectional survey and cluster analysis. International Journal of Mental Health Systems, 13(1), 3.

Tromholt, M. (2016). The Facebook experiment: Quitting Facebook leads to higher levels of well-being. Cyberpsychology, Behavior, and Social Networking, 19(11), 661-666. https://doi.org/10.1089/cyber. 2016.0259.

Van Reeth, O., Weibel, L., Spiegel, K., Leproult, R., Dugovic, C., \& Maccari, S. (2000). PHYSIOLOGY OF SLEEP (REVIEW)-Interactions between stress and sleep: From basic research to clinical situations. Sleep Medicine Reviews, 4(2), 201-219.

Wolniczak, I., Cáceres-DelAguila, J. A., Palma-Ardiles, G., Arroyo, K. J., Solís-Visscher, R., Paredes-Yauri, S., Mego-Aquije, K., \& Bernabe-Ortiz, A. (2013). Association between Facebook dependence and poor sleep quality: A study in a Sample of undergraduate students in Peru. PLoS ONE, 8(3), e59087.

Xanidis, N., \& Brignell, C. M. (2016). The association between the use of social network sites, sleep quality and cognitive function during the day. Computers in Human Behavior, 55, 121-126.

Zaffar, M., Mahmood, S., Saleem, M., \& Zakaria, E. (2015). Facebook addiction: Relation with depression, anxiety, loneliness and academic performance of Pakistani students. Sci Int (lahorE), 27(3), 2469-2475.

Zhang, M. W. B., Tran, B. X., Huong, L. T., Hinh, N. D., Nguyen, H. L. T., Tho, T. D., Latkin, C., \& Ho, R. C. M. (2017). Internet addiction and sleep quality among Vietnamese youths. Asian Journal of Psychiatry, 28, 15-20.

Publisher's Note Springer Nature remains neutral with regard to jurisdictional claims in published maps and institutional affiliations. 